\title{
Water Scarcity: A Fact or Fiction for a Coastal Village of Bangladesh!!
}

\section{Dr. Sohela Mustari}

Assistant Professor, School of Business Studies, Southeast University, Banani, Dhaka, Bangladesh

Email: smustari@seu.ac.bd

\section{Dr. A.H.M.Zehadul Karim*}

Professor, Department of Sociology and Anthropology, IRKHS, International Islamic University Malaysia (IIUM) Gombak, Malaysia; *Corresponding Author Email: ahmzkarim@yahoo.com

\section{Doi:10.5901/mjss.2016.v7n4p695}

\begin{abstract}
This paper sets out an examination of natural disaster amongst coastal villagers in a developing country, and presents the nature of social vulnerability in collecting drinking and fresh water in their everyday life. Global climate change and geographical location of coastal Bangladesh effects on societal people by creating constraints in having fresh water. To know the nature and sufferings in collecting and getting fresh water, this research used 30 in-depth interviews from the villagers and the intellectuals. Three more Focus Group Discussions were triangulated to increase the reliability of the collected data.
\end{abstract}

Keywords: Vulnerability, Coastal village, Bangladesh, Natural disasters, Water scarcity.

\section{Introduction}

Water is considered as one of the most important resource for human development. However, water scarcity has become the most concern for Asian countries, particularly in agriculture dependent countries like Bangladesh. Despite this, in Bangladesh water scarcity is considered as the ultimate result of climate change. This water crisis has significant impact in determining their livelihood activities, household resources and woman's role.

A number of observers have argued that experience of natural disasters is considered as routine event for Bangladesh coastal areas (Islam, Kamaruddin, Ahmad, Jan, \& Anuar, 2016; Mahmud, \& Mbuya, 2016). For a long period, coastal people of Bangladesh are living with natural disasters like cyclones or tidal surges (Alam \& Collins, 2010). Although apparently these disasters seem to them scheduled events but the reality is, the frequency of natural disasters and their impacts on socio-economic lives have increased a lot than before. Global warming causes the mountain glaciers to melt faster and increases the level of sea water, which reduces the availability of fresh water drastically. Saline water mixes with the inland as it comes inside with the cyclone and tidal surge (Shamsuddoha, \& Chowdhury, 2007). Water is vital for these coastal people, not only for drinking purpose but also for other everyday activities like agriculture, industry and even for household activities. Lack of fresh water in all these sectors hinders the development of human society, in specific coastal community (Lal, 2000).

"The large populations in many coastal areas around the world are, to a greater or lesser extent, vulnerable to weather-related hazards" (Klein, Nicholls \& Thomalla, 2003).These coastal areas are experiencing freshwater scarcity all over the world due to complex and faster change of natural supply of water. Many research has shown that this scarcity which will increase the demand of fresh water tremendously by causing socio-economic vulnerabilities by 2015 (Vörösmarty, Green, Salisbury, \& Lammers, 2000). In some reports (Watkins, 2006)it is discovered that almost every year, around 2 million children breathe their last breath in need of fresh drinking water. Obviously the scenario is even worse for a country which is from the least developed region. Secondary sources (e.g.,Watkins, 2006; Rijsberman, 2006) further mentioned that people of poor country will face the difficulties in the absence of natural and fresh water supplies, as it will bring social problems like increased female working hours, health problems and decreased economic production. Though Rijsberman (2006) did not consider water scarcity as a global problem, but he admitted that this water scarcity is very much related in creating food production and other household necessities. He further added thatthis lack of water availability is not a problem for all the countries in general. Those countries which are over populated and becomes barren easily, face the water scarcity problem. For example, a country of Central and West Asia or North Africa becomes dry and experiences fresh water scarcity. Like Rijsberman (2006), Arnell (2004) also believed that the water crisis is not a 
global phenomenon as it is not equally true for all the countries. However, he did not forget to warn that due to global climate change issues, the water scarcity and related problems from it will increase and spread out in near future. By using climate projection models he showed that in 1995 around 1400 million people were facing water scarcity, whereas by 2025 the number will increase to 2.9 to 3.3, which is an alarming number as it will cover $36-40 \%$ of total world people (Arnell, 2004).A few years before of Arnell(2004),Seckler, Barker, \& Amarasinghe, (1999) estimated that "nearly 1.4 billion people, amounting to a quarter of the world's population or a third of the population in developing countries, live in regions that will experience severe water scarcity within the first quarter of the next century" (Seckler, Barker \& Amarasinghe, 1999). So the number of vulnerable people is increasing.

\section{Literature Review}

Previous literatures applied the word vulnerability to show the sufferings whichresult from natural disasters (Bryant and Bailey, 1997). Vulnerability from a socio-ecological perspectives focus on the understanding that social vulnerability is the artifact of natural hazards (Pelling \& Uitto, 2001). Pelling \& Uitto (2001) in their paper these researcher wanted to identify coastal villagers vulnerability based on their quality of living such as their housing quality, infrastructural settlements, security of basic human necessities and other preparedness to reduce the vulnerabilities.

A nature dependent coastal community like Coqueiral of northeastern Brazil has the primary dependency for their economic activities on fishing from the sea(Forman, 1967). These nature dependent fishing communities face extreme sufferings if the water crisis increases due to world climate change. To illustrate the sufferings a number of researchers said that the crisis will lead towards political instability and will increase more as international conflicts for common water sources (Ohlsson, 2000, Salehyan, 2008). Of central Asian countries water scarcity is the result of drought and barrenness. This water scarcity causes damage for their agriculture (Pereira, Cordery, \& lacovides, 2009).But some researchers described the relationship between water scarcity and agriculture in other ways. Pereira, Paredes, Cholpankulov, Inchenkova, Teodoro, \& Horst (2009) specified that the reason of dryness of this region is the excessive use of water in agriculture. Few research (Oweis \& Hachum, 2006) considered water, instead of lands as the most important resource for an agriculture based community. So these researchers suggested to adopt proper water management strategies so that agricultural production and livelihood of community people can run smoothly.

Some researchers considered water scarcity as a neglected issue in academic and policy research areas. In specific researchers are not concerned to know the vulnerability in getting fresh water of a coastal village people in a developing country like Bangladesh. However, some sources are declaring that salinity as an effect of sea level rise or cyclones and floods are causing a number of vulnerabilities for a coastal village (Chong, Khan, Scheelbeek, Butler, Bowers \& Vineis, 2014; Mustari, \& Karim, 2014; Sohela, 2013).

\section{Research Objectives}

1. To know the vulnerability of coastal people in collecting fresh drinking water in their everyday life.

2. To know the differences in their vulnerability in having fresh drinking water due to their socio-demographic differences.

\section{Methodology}

\subsection{Research design}

Before designing this research, this author visited the field site informally several times in July 2011. The aim of those informal visits was to learn about a practical field scenario. During those visits, the researcher chatted with the villages of Gabura union to learn about some experiences that they face due to natural disasters throughout their lives. After those field visits this research relied on some secondary sources.

\subsection{Selection of the study area}

This research was conducted in a village named Napitkhali located in the Gabura Union of Satkhira District of Southwestern Bangladesh. This researcher preferred to work with this coastal people so that their vulnerability in their livelihood options, specifically, vulnerability in collecting fresh drinking water can be done. 


\subsection{Selection of respondents}

The purpose of this study is to know the vulnerabilities in having fresh drinking water that the coastal people of Bangladesh face due to natural disasters in their everyday life. In this context, all the basic socio-demographic information of the villagers was collected with a social survey from the entire Napitkhali village of Gabura union, Satkhira District. The aim of this survey was to give a brief and a transparent idea about the coastal life. In addition to this a total 30 in-depth interviews were taken from the villagers and also from the intellectuals. Apart from these three Focus Group Discussions were taken to triangulate the data. This is how this research increases the reliability and validity of the collected data.

\subsubsection{Findings 1}

The general aim of this study is to know the vulnerabilities of the coastal people in Bangladesh which they face in collecting drinking water in their everyday life. For this purpose, a small village named Napitkhali containing 140 households was chosen. This part of this article thus reports the socio-demographic descriptions of the entire village compiled through an extensive survey. The aim of this part is to give a brief and a transparent idea about the coastal life in general in rural Bangladesh.

Table 1: Demographic description of Napitkhali villagers.

\begin{tabular}{|c|c|c|}
\hline Age diversification among the household heads(in years) & $\begin{array}{l}20-29 \\
30-39 \\
40-49 \\
50-59 \\
60-69 \\
70-79 \\
80-89\end{array}$ & \begin{tabular}{|c|}
$12.14 \%$ \\
$39.29 \%$ \\
$20.71 \%$ \\
$12.86 \%$ \\
$5.00 \%$ \\
$9.29 \%$ \\
$0.71 \%$ \\
\end{tabular} \\
\hline Educational attainment of Napitkhali household heads & $\begin{array}{l}\text { Non-lettered } \\
\text { Signature only } \\
\text { Primary level } \\
\text { Secondary level } \\
\text { Higher secondary and above }\end{array}$ & \begin{tabular}{|c|}
$57.14 \%$ \\
$12.15 \%$ \\
$20.71 \%$ \\
$9.29 \%$ \\
$0.71 \%$ \\
\end{tabular} \\
\hline Occupational diversification of household heads & $\begin{array}{l}\text { Fishing } \\
\text { Labourers } \\
\text { Business } \\
\text { Politics } \\
\text { Housewife } \\
\text { Boatman } \\
\text { Retired } \\
\text { Jobless (due to physical disability) }\end{array}$ & \begin{tabular}{|c|}
$80 \%$ \\
$10 \%$ \\
$2.86 \%$ \\
$0.71 \%$ \\
$2.86 \%$ \\
$0.71 \%$ \\
$1.43 \%$ \\
$1.43 \%$ \\
\end{tabular} \\
\hline Income among Napitkhali household heads(in Tk) & $\begin{array}{l}0-4,999 \\
5,000-9,999 \\
10,000 \text {-above }\end{array}$ & \begin{tabular}{|c|}
$69.99 \%$ \\
$26.44 \%$ \\
$3.57 \%$ \\
\end{tabular} \\
\hline Main source of fishing and Napitkhali household heads & \begin{tabular}{|l} 
River \\
Sea \\
Forest Sundarban \\
Pond \\
Shrimp field \\
Other sources \\
\end{tabular} & \begin{tabular}{|c|}
$20 \%$ \\
$14.29 \%$ \\
$62.14 \%$ \\
$0.71 \%$ \\
$0.71 \%$ \\
$2.14 \%$ \\
\end{tabular} \\
\hline
\end{tabular}

Source: From author's unpublished article where it was mentioned that the data was collected through "Household survey (2013)"

\subsubsection{Findings 2}

Various natural disasters like long summer, increased temperature, short monsoon, monsoon with heavy rainfall or no pre-monsoon cause vulnerability of water resources. Professor Tarekul Islamof Institute of Water and Flood Management 
(IWFM) specified that "The effects of climate change on coastal areas will increase in the near future more and more. The adaptation to these new situations is not so easy for these people".

The villagers of Napitkhali believe that saline water itself is a not a natural disaster for them. However, they know that it is a consequence of other natural disasters like increase sea level, cyclones, floods or river bank erosion. A middle class villager Shah Jamal Morol said that during the dry season the saline water causes more vulnerability as saline comes out from the ground. During the rainy season, he added, this saline is washed away by rain water. Shah Jamal Morol said:

We are used to see the natural disasters. If you go to the river side, you can see, the tidal wave is not normal like other river. Erosion occurs continuously some part of the river. This riverbank erosion brings unwanted flood and salinity with it. This tidal flood happens minimum twice in a year. In Bangla Chaitra (March-April), the water scarcity raised in high.

Water isan element which is needed every day for drinking purpose. In Gabura the scarcity of water is severe. From informal discussion with the villagers it was known that, after cyclone Aila many of them did not get any drinking water for about 18 months consecutively. Muhammad Habibur Rahman, a migrated villager, said that at that time they had water everywhere but the water wasfilled by saline water. He further said that all the indigenous sources of water such as the ponds were also full of saline. If they need to collect drinking water they need to cross the river by boat which is costly, time consuming, hardwork and hazardous. He considered it as hazardous because during the rainy season it is very risky to cross the river. Muhammad Habibur Rahman Sardar said:

We try to keep some rain water to use it in dry season. But the dry season is so long 5 to 7 months. So we need to buy supply water from the Non-government Organization. We need to pay 10 taka per month to take 1 jar of water in each day. But for my shop purpose I need to take one more jar of water. For that reason I need to pay them 25 taka. Each jar of mine contains 8 to 10 litres of water. This water supply in Chaitra-Boishakh (March-May) is not regular. Sometimes without any prior notice, they stopped supplying drinking water. The other household activities like cooking, washing, bathing purpose, we use pond, river or tube well water which is salt in taste. My wife collects this water from all the sources. Sometimes my son and daughter also help their mother.

Mohammad Mosharraf Morol said that after cyclones Aila and Sidr, his family needed to drink absolute saline water. But, he said that with high tide cyclones, it brought salt water with it from the sea. He stated that this sea water is mixed with all water sources like rivers, ponds and fields. Though there is a number of tube-wells in front of their houses and other neighbours' houses only salt water came out of these. He acknowledged that considering their vulnerabilities due to drinking water scarcity, a number of organizations have come forward. Mohammad Mohiuddin of CDMP also said, "Our organization worked with this village. For their drinking purpose, we use PSF (Pond Sand Filter) or the water supply center". Then Mohammad Mosharraf Morol again said that his family and other neighbours get drinking water from that center. But he added, for other household works like washing, bathing or cooking purposes, they use the salty water. Mohammad Mosharraf Morol said:

\begin{abstract}
In rainy season we collect water from the rain. In summer season we collect the supply water with specific payment. We need to pay 15 taka per month to have fresh water. However, if sometimes I fail to pay the money, they stopped to give others fresh water. In the same way, if the demands of water increases, they reduce to give us ample water according to our demands. Then we need to give supplement with the tube-well water. Some NGO suggested us to boil the water to make the tube-well water fresh. But it failed, because if we boil the saline water, it becomes salty, not fresh water.
\end{abstract}

Field data indicate that most of the villagers prefer the rainy season instead of the dry season because Md. Rejaul Morol stated that during the rainy season they can avoid salinity. In addition, in general during the rainy season, they can collect drinking water from the rain. But due to climate change, the rain also comes late or sometimes early which causes vulnerabilities in other sectors. However, in general he mentioned that they prefer the rainy season in terms of getting fresh drinking water. Like many other villagers, however he does not have drums to collect fresh rain water. In this regardMd. Rejaul Morol's statement is commendable. He said:

Water scarcity is huge here and for that reason, I migrated to town. Although in the towns, we need to pay money for water, but there through supply water at least, we get fresh water. Here in our village also we need to pay money on monthly basis but we get only one bucket water per day. While we can collect rain water in rainy season. I didn't manage to buy drum yet to collect rain water, but I have a big clay pot where 4 bucket of rain water can be collected. My wife or daughter in-law collects this water for my family. 
The common villagers are aware of the climate change. They can understand it through their indigenous observation. One of the villagers, Wayes Karim said that normally, during the rainy season it should be raining everyday but because of climate change the trend has changed. As a consequence, the Napitkhali villagers are experiencing different sufferings compare to other villagers in non-coastal districts of Bangladesh. He said further that traditionally water in his village was freely accessible. However, climate change effect has caused them to experience a different situation. Wayes Karim stated:

\begin{abstract}
I can't explain you how much we suffer with water problem. In summer season we suffer badly with drinking water. Everywhere around us, we have water but we can't drink that. Because all sources of water is full of saline water. Then we have no alternative except depending on the purchased water. We buy water from the water supplier. Per pail they charged 15 taka in a month. That water is sweet and fresh because they use long pipe to bring the ground fresh water.
\end{abstract}

Drinking water scarcity is acute here. Due to this scarcity, the most vulnerable group is the female members of the household. Researcher Mohammad Mohiuddin said, "Like many other underdeveloped and developing countries, female members of this region are responsible for collecting drinking water. These female members of south-western coast of Bangladesh need to walk or need to ride the boats 5 to $7 \mathrm{~km}$ every time. With this they are losing a lot of personal time. They are getting delay in finishing their household works with this pressure". Rebeca Khatun (Bewa) said that as she cannot bring all her children with her, those who stay at home, remain uncared for. Furthermore, it is not uncommon in her society to face social harassments on the way to collecting water. In this concern, Rebeca Khatun (Bewa), this widow with two kids shared her vulnerability regarding drinking water scarcity. She said:

\begin{abstract}
My husband passed away with a kidney disease. When my husband became sick, everyone suggested avoiding saline water. But after Aila around one year our area was under saline water. How could I give him fresh water? However, I tried my best to manage fresh water by going a long way in another village. Almost every day I went this long way to collect fresh water. Even if it was not possible to go every day, I kept some water for my husband. But I with my small kids continued to drink that salty water.
\end{abstract}

She shared her experience of water collection by saying:

Now in our village one organization put supply water for dry season. However as I am a widow, people say bad things if I go outside for everything. My daughter is now seven years old, so she helped me in collecting water from that supplier. However if I go for water collection, I need to keep my younger son with the responsibility of my daughter.

\title{
4.3.3 Findings 3
}

An academic Abul Kalam Azad from the Institute of Disaster Management and Vulnerability Studies (IDMVS) said, "Drinking water is a challenging issue for this community. To solve the problem, the government provides them tube-well but unfortunately, this tube well is set up in a house who has influence on the society. So the community people and the masses do not have easy access to this water anytime as they wish. Rather, they need to wait for the house owner to get their permission". One of the rich villager's statement proved the intellectual's claim. Md. Mizan Sardar left the village because of enormous vulnerabilities but still does his shrimp business in this village. He said that the tube-well which they have in Napitkhali is full of salty water which they cannot drink. They can only cook and do other household works with this. So he contacted the proper authority and managed to have a big water tank for the villagers. Though he changed his residence which is on the other side of the river and a few kilometer away from Napitkhali he managed to have a big tank of fresh water in his house to help the Napitkhali villagers. Md. Mizan Sardar, this rich farmer of Napitkhali, who no longer live in this village, stated:

When we live in this Napitkhali like many others we had drinking water crisis. After shifting from here, in new place we had the crisis as well but less than before. I communicate with the organizations to solve our water crisis. Then they established a tank in my homestead and we fill the tank with the pond water and filtered it with the given instruction which is fixed by the organization man. Many people of this Napitkhali village cross the river by boat and collect water from my house for free.

Dilara Zahid, an expert in natural disasters and society, said, "Traditionally Bangladesh villages have maintained a discrimination of work pattern in their household. Napitkhali is also not unique from that inclination". It is found that the male members remain engaged in outsourcing work for their living. On the other hand, the females of the household 
endure household works, like child rearing, bearing and cooking. In those patterns of work, collecting drinking water is also considered by the Napitkhali villagers as the duty of the female members. In the first FGD, the male household heads agreed that the toughest job of collecting fresh water is done by the female members of their families. All of these six respondents stated that the female members had to wait a long time in line to get water from the supplier. Sometimes these females need to walk a long way with their pail in their laps, this work becomes physically a burden for them. Moreover, two of the respondents mentioned that the suppliers' with their modern equipment can be unsuccessful in providing fresh water during summer season. This is acute when the water level goes down. These is not infrequent according to them but if there is problem with the machines then the villagers need to pay extra money to repair it. If they cannot pay, sometimes the summer season goes by without having fresh water.

Since Napitkhali is a coastal village in Bangladesh, having fresh drinking water everyday is also dependent on nature. In the second FGD, all six respondents mentioned that their supply of drinking water relies mostly on type of seasons. If it rains in their village, they can get fresh drinking water from the rain. Otherwise they need to drink saline water from the tube-wells. Moreover, this schedule is often disrupted if any severe natural disasters like cyclones or floods appear. During the time of Aila, many of them said that they had to remain without fresh water for several months. Two or three of the respondents said that they could manage drinking water but it was expensive to bear the communication costs. Similarly, it was discovered that lack of proper drinking water is also a reason behind their absence of livestock and poultry. Somehow, the villagers could manage to get fresh water for themselves but are unable to share it with their livestock.

\section{Discussion}

\subsection{Fresh drinking water and water scarcity in coastal village}

Napitkhali village is a remote coastal village of Bangladesh. The reason of drinking water crisis in this village is the natural disasters. For drinking water purpose traditionally the villagers are used to collect fresh water from tube-well. However as natural disasters like sea-level rise, cyclones, floods or river bank erosion occurs frequently due to both the climate change effect and historical episode, the traditional way of collecting drinking water has changed. This community does not have supply water like the urban people. So in rain season to have drinking water, these people depend on rain water whereas in dry season when the water level goes down they collect drinking water from the non-government supply water. This supply water is given to support the whole community.

\subsection{Fresh drinking water and increased women workload}

The participants from the first two FGDs mentioned that cyclones, floods and river bank erosions are the most common natural disasters in this community. The other FGD was not unlike the first two FGDs. All these 18 participants of three FGDs talked about their vulnerable ecology in terms of getting pure drinking water. As the female members are in the responsibility of household maintenance, traditionally collecting drinking water for household purposes are also considered as the task of the women and girls of the family. So the women and girls need to walk miles or ride on boat in absence of water supply during summer. Even, if they have common source supply water, it was found that the women's workload increases as they need to wait in the long queue to get drinking water. This water supply comes from the depth of the ground water with modern technology. This means the over consumption of ground water can direct to the contamination of arsenic water.

\subsection{Fresh drinking water and increased household expense}

Monthly each household needs to pay Taka 10 to Taka 20 for per pail of water. This extra expense create a kind of burden for this low income people. To avoid this expense, many of the villagers do not use supply water and look for alternatives. Even it is not unusual for them that if they fail to manage any alternative source of fresh water, they take the available saline water directly. However many of the respondents expressed that in dry season the water scarcity is so acute that even with payment they cannot get fresh drinking water.

\subsection{Fresh drinking water and available coastal water sources}

The saddest experience of Bangladesh coastal villagers is that they have water all around them but they suffers from 
having safe water very badly. Though some NGO's and other organizations are trying to provide them fresh water but that water is very insufficient compare to their requirements. These organizations provide them only the drinking water and only for few months, not regularly throughout the year. So for other purpose, for example, in other household works they need to use available unhealthy water.

\subsection{Fresh drinking water and poultry and livestock}

Napitkhali is a coastal village of Bangladesh which is surrounded by water in its all sides. But these water sources are polluted with saline as cyclone and floods causes sea water to come and mix with the ground water. Though these villagers do hard work to collect fresh drinking water for their own but they are not able to share it with their poultry or livestock. As a result of this, lack of fresh water thwarts them from any home based poultry or livestock farming. Indigenous livelihood is thus hampered with absence of fresh drinking water.

\subsection{Fresh drinking water and migration}

Temporary migration is a common scenario in Napitkhali. Many of the respondents that scarcity of fresh drinking water and as well as fresh water in other household and economic use, bounds them to think for alternative. Among some others they prefer the alternative to go for temporary migration to avoid the drinking water scarcity during the summer season. They come back again, once the rainy season hash out in their own place.

\subsection{Fresh drinking water and health}

Scientific resources declared that having too much saline water and unsafe water causes health problems like diarrhea, skin diseases, high blood pressures and even kidney diseases. This statement was found as true as a number of respondents agreed of suffering with all these diseases which may resulted from having not fresh drinking water.

\subsection{Fresh drinking water and different demographic features}

Both the in-depth interviews and the Focus Group Discussions with the villagers revealed that the primary impacts of natural disasters are equal for all the villagers regardless of their socio-demographic background. Living in low land, all the inhabitants equally suffer the scarcity of drinking water, but their level of sufferings vary based on their sociodemographic characteristics. The rich are able to buy water filter for personal use but the poor cannot. Similarly the rich get the advantage in collecting the supply water also. The rich need not to wait in the queue and if they come lately they receive advantage in collecting water directly without waiting in the queue. Moreover most of the time because of their strong network, rich get advantage in having tube-well in their own place. So they need not to walk a long distance like the poor.

The most vulnerable group in terms of collecting drinking water is the female members of the household. Those who are widow or head of the household are more vulnerable than the other general female of the village. They need to think about their kids, they need to bring the kids with them or sometimes they face social harassment on the way to collect drinking water.

\section{Conclusion}

As it is evident from the available data that coastal region of Bangladesh is undergoing rapid environmental changes compare to its mainland. Similarly, Bangladesh coastal areas are different from many other coastal areas of the world because the vulnerabilities that coastal people faces, most of the developed countries are able to recover with their planning and policies. But a coastal village from a developing country like Bangladesh is not prepared enough to cope with the drinking water scarcity.

From all point of view,to an increase scarcity of drinking water has negative implications on current and future rural development of Bangladesh. Water management authority should develop proper policies to reach the target development so that each and every single member of coastal villages can access fresh drinking water. The result shows that the vulnerability of Napitkhali villagers due to the scarcity of drinking water is not standardized for all as it differs based on their socio-demographic characteristics. Moreover this crisis of drinking water brings a number of related sufferings in their social life. So finally, the paper proposes to conduct more multidisciplinary research on water scarcity 
and its effect on rural life so that policy makers can access a clear idea to provide potential benefits to the coastal people of Bangladesh.

\section{References}

Alam, E., \& Collins, A. E. (2010). Cyclone disaster vulnerability and response experiences in coastal Bangladesh. Disasters, 34(4), 931954.

Arnell, N. W. (2004). Climate change and global water resources: SRES emissions and socio-economic scenarios. Global environmental change, 14(1), 31-52.

Bryant, R.L., Bailey, S., 1997. Third World Political Ecology. Routledge, London.

Chong, Y. J., Khan, A., Scheelbeek, P., Butler, A., Bowers, D., \& Vineis, P. (2014). Climate change and salinity in drinking water as a global problem: using remote-sensing methods to monitor surface water salinity. International Journal of Remote Sensing, 35(4), 1585-1599.

Forman, S. (1967). Cognition and the catch: the location of fishing spots in a Brazilian coastal village. Ethnology, 417-426.

Islam, R., Kamaruddin, R., Ahmad, S. A., Jan, S. J., \& Anuar, A. R. (2016). A Review on Mechanism of Flood Disaster Management in Asia. International Review of Management and Marketing, 6(1), 29-52.

Klein, R. J., Nicholls, R. J., \& Thomalla, F. (2003). Resilience to natural hazards: How useful is this concept? Global Environmental Change Part B: Environmental Hazards, 5(1), 35-45.

Lal, M. (2000). Climatic change-implications for India's water resources. Journal of Social and Economic Development, 3, 57-87.

Mahmud, I., \& Mbuya, N. (2016). Water, Sanitation, Hygiene, and Nutrition in Bangladesh.

Mustari, S., \& Karim, A. H. M. (2014). Impact of Salinity on the Socio-Environmental Life of Coastal People of Bangladesh. Asian journal of social sciences \& humanities, 3(1), 12-18.

Ohlsson, L. (2000). Water conflicts and social resource scarcity. Physics and Chemistry of the Earth, Part B: Hydrology, Oceans and Atmosphere, 25(3), 213-220.

Oweis, T., \& Hachum, A. (2006). Water harvesting and supplemental irrigation for improved water productivity of dry farming systems in West Asia and North Africa. Agricultural Water Management, 80(1), 57-73.

Pelling, M., \& Uitto, J. I. (2001). Small island developing states: natural disaster vulnerability and global change. Global Environmental Change Part B: Environmental Hazards, 3(2), 49-62.

Pereira, L. S., Paredes, P., Cholpankulov, E. D., Inchenkova, O. P., Teodoro, P. R., \& Horst, M. G. (2009). Irrigation scheduling strategies for cotton to cope with water scarcity in the Fergana Valley, Central Asia. agricultural water management, 96(5), 723735.

Pereira, L. S., Cordery, I., \& lacovides, I. (2009). Coping with water scarcity: addressing the challenges. Springer Science \& Business Media.

Rijsberman, F. R. (2006). Water scarcity: Fact or fiction?. Agricultural water management, 80(1), 5-22.

Shamsuddoha, M., \& Chowdhury, R. K. (2007). Climate change impact and disaster vulnerabilities in the coastal areas of Bangladesh. COAST Trust, Dhaka.

Seckler, D., Barker, R., \& Amarasinghe, U. (1999). Water scarcity in the twenty-first century. International Journal of Water Resources Development,15(1-2), 29-42.

Salehyan, I. (2008). From climate change to conflict? No consensus yet.Journal of Peace Research, 45(3), 315-326.

Sohela, M. (2013). The Challenges and Coping Strategies of 'Mowal'the Honey collectors of Sundarban. Bangladesh. International Research Journal of Social Sciences, 2(6), 7-11.

Vörösmarty, C. J., Green, P., Salisbury, J., \& Lammers, R. B. (2000). Global water resources: vulnerability from climate change and population growth.science, 289(5477), 284-288.

Watkins, K. (2006). Human Development Report 2006-Beyond scarcity: Power, poverty and the global water crisis. UNDP Human Development Reports (2006). 